\title{
Historical perspectives of The American Association for Thoracic Surgery: Robert Edward Gross (1905-1988)
}

\author{
Joseph W. Turek, MD, $\mathrm{PhD},{ }^{\mathrm{a}}$ and J. William Gaynor, $\mathrm{MD}^{\mathrm{b}}$
}

Robert Edward Gross served as the 44th President of The American Association for Thoracic Surgery (AATS) (Figure 1). In his presidential address delivered in April 1964 , the man considered by many to be the father of cardiac surgery offers us a glimpse into his motivation for a life's work in his talk titled "Thoracic Surgery for Infants." " "The challenge is great; the rewards are enormous. For me there have been few things in life which have been more satisfying than to face a small child, struggling for his very existence, to perform some corrective surgical maneuver, and later to see the youngster, thriving and healthy, starting out in life, sound in body and mind."

Gross' contributions to the field of thoracic surgery remain unparalleled. Through his pioneering work on even the smallest of patients, he founded pediatric cardiac surgery and, in the process, laid the groundwork for the development of a viable surgical specialty in the adult. His career embodied the utmost in surgical leadership, through a rare combination of excellence in surgical technique, clinical innovation, scientific research, and teaching.

Born on July 2, 1905, in Baltimore, Maryland, Gross seemed an unlikely candidate for a surgical pioneer. $\mathrm{He}$ was the seventh of 8 children, the son of a German immigrant piano maker. Gross suffered from a congenital cataract and, as a result, had no vision in 1 eye. His father would give him clocks to take apart and put back together as an exercise to train him to develop depth perception with a single functioning eye. In addition to refining his fine motor skills, it instilled in him a love for tinkering that persisted throughout his days. ${ }^{2}$

Gross was an outdoorsman growing up, choosing to spend summers in central Minnesota performing farmhand work. This undoubtedly influenced his choice to attend Carleton College in Northfield, Minnesota. At Carleton, Gross majored in chemistry but soon redirected his focus toward medicine after reading Harvey Cushing's biography of Sir William Osler. He excelled at the premedical curriculum,

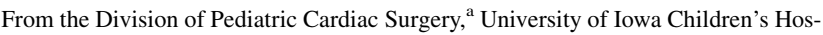
pital, Iowa City, Iowa; and Division of Cardiothoracic Surgery, ${ }^{b}$ Children's Hospital of Philadelphia, Philadelphia, Pa.

Disclosures: Authors have nothing to disclose with regard to commercial support.

Received for publication Jan 9, 2012; accepted for publication Jan 24, 2012; available ahead of print Feb 20, 2012.

Address for reprints: J. William Gaynor, MD, Division of Cardiothoracic Surgery, Children's Hospital of Philadelphia, 34th and Civic Center Boulevard, Philadelphia, PA 19104 (E-mail: gaynor@email.chop.edu).

J Thorac Cardiovasc Surg 2012;143:1003-6

$0022-5223 / \$ 36.00$

Copyright (c) 2012 by The American Association for Thoracic Surgery doi:10.1016/j.jtcvs.2012.01.065
}

was inducted into the Phi Beta Kappa honor society, and graduated with honors.

After graduation, he entered Harvard Medical School, by his own admission, to follow Professor Cushing. However, his most influential experience as a student in Boston came during a fourth year elective surgical rotation at Children's Hospital with surgeon-in-chief, William E. Ladd. Gross graduated Harvard Medical School in 1931 as a member of Alpha Omega Alpha and elected to pursue postgraduate training with Simeon Burt Wolbach, chairman of the Department of Pathology at Harvard Medical School. These 2 years proved to be tremendously valuable, because he developed an intimate knowledge and affinity for the anatomy of the heart and great vessels by conducting hundreds of autopsies under Wolbach's tutelage.

Armed with a unique appreciation and knowledge of cardiac anatomy, Gross began his surgical residency at Peter Bent Brigham Hospital in 1933. His interest in the heart and great vessels was further stimulated by Brigadier General Elliott Carr Cutler. Cutler, who had succeeded Harvey Cushing as surgeon-in-chief the previous year, had a particular interest in surgery on the heart. In the early 1920s, Cutler directed the Harvard surgical research laboratory and in 1923 performed the first successful surgical procedure for the treatment of mitral stenosis. ${ }^{3}$ Cutler was well aware of Gross' interest in pediatric surgery and awarded him the 1937 George Gorham Peters traveling fellowship to study at the Royal Hospital for Sick Children in Edinburgh.

On returning from Scotland in 1938, Gross was selected by Ladd to serve as chief surgical resident at Children's Hospital. Immediately, Gross set his sights on devising a surgical approach to the ligation of the patent ductus arteriosus. ${ }^{4}$ Along with the assistance of pediatrician John Hubbard, Gross immersed himself in the animal laboratory and autopsy suite until an efficient and reproducible surgical strategy had been developed. The famed story of the first successful operation, performed by chief resident Gross, despite the absence of Ladd on vacation, has been retold to countless surgical trainees. In an unpublished autobiography now housed in the Countway Library of Medicine in Boston, Gross, in his own words, recounted the events surrounding the first successful ligation of a patent ductus arteriosus:

"As time went on there was an urge to attack several blood vessel anomalies which had been seen previously at autopsies during my training two years before. The first consideration had to do with possibly attacking a ductus arteriosus that had remained 


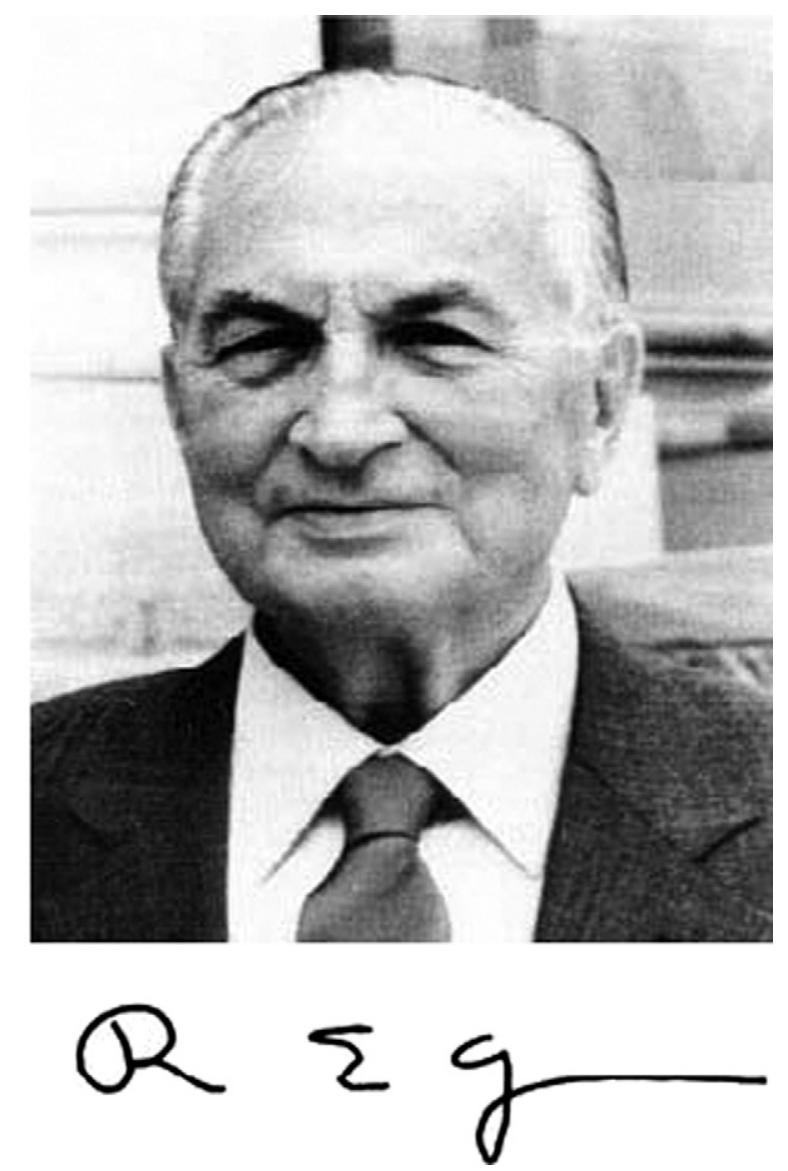

FIGURE 1. Dr Robert Edward Gross, 44th President of the American Association for Thoracic Surgery (courtesy of the Children's Hospital Boston Archives).

patent. How could one be closed off surgically? It had never been accomplished anywhere before. Possible surgical approaches to a ductus were practiced on humans in the autopsy room and on animals. Our first operation for such a procedure was performed on a 7-year-old girl on August 26, 1938. The postoperative course was uneventful and without worry. The next morning, she was up and out of bed and around the ward. She was discharged in 10 days. Our patent ductus operations were always done through a left anterolateral approach through the third intercostal space."

That 7-year-old girl is now an 80-year-old woman and recently reminisced about Gross and her experience. "I remember the day of the surgery going up in the operating room. I can remember looking up and seeing all these men looking down... . I went to sleep and the next thing I woke up. I was in my crib. I was seven and a half years old." After her surgery, she remained in touch with Gross, and remembered, "We were going someplace and he looked over and he said, 'Lorraine you know, if you didn't survive,
I'd end up as a chicken farmer in Vermont!' I said, 'Well doctor, thank God I come from good Irish stock!",5

Gross did not hesitate in identifying his next conquest in pediatric heart surgery: surgical treatment of aortic coarctation. Later, in 1938, along with resident colleague Charles Hufnagel, he initiated a series of animal experiments whereby a short segment of abdominal aorta was resected, with the remaining ends anastomosed. The early studies were complicated by hind leg paralysis, but by mid-1939, using a refined surgical technique and hypothermia, successful experimental outcomes were achieved. These studies were on display later that year during a visit from the highly esteemed Swedish surgeon, Clarence Crafoord. However, the course of the Second World War delayed Gross' plans to apply this technique in humans. Thus, it was not until 1945 that Crafoord and Gross, within 1 month of each other, published the results of successful corrections for coarctation of the aorta. ${ }^{6,7}$ Crafoord's operation was performed 8 months before Gross' first coarctation repair. Gross was convinced his technique had been stolen. As a result, soon after Crafoord's publication was released, Gross closed his laboratory to all visitors. ${ }^{8}$ In other experiments, Gross and colleagues devised techniques for preserving and sterilizing aortic homografts to replace diseased segments of aorta; work that has proved to have lasting implications in the reconstruction of the great vessels. ${ }^{9,10}$ Within the same year, with an extensive laboratory and clinical experience with defects of the great vessels, Gross became the first to describe the management of the double aortic $\operatorname{arch}^{11}$ and, soon after, various other vascular rings. ${ }^{12}$

In 1947, at only 42 years old, Gross assumed the role of surgeon-in-chief at Children's Hospital in Boston, a position that he held for the ensuing 20 years. By 1952, his technical innovations were legendary, as he demonstrated in the development of his ingenious atrial well technique for closure of atrial septal defects. At this time, the burgeoning field of cardiac surgery was mostly limited to closed heart repair. Open heart surgery was considered the next frontier. While awaiting laboratory refinement of cardiopulmonary bypass, a number of techniques emerged. Charles Bailey was using a "doughnut" technique to suture the right atrial free wall circumferentially around the atrial septal defect in a closed heart fashion. Surgeons at the University of Minnesota were using a combination of inflow occlusion and hypothermia to repair such defects. In Boston, Gross introduced his atrial well as an alternative. ${ }^{13}$ During the operation, a generoussize rubber well was sewn to the right atrium, effectively increasing the capacity of the chamber to hold low-pressure atrial blood without overflowing (Figure 2). This allowed closure of the defect by placing sutures in the rim of the defect under digital guidance.

When clinical use of cardiopulmonary bypass was first introduced, Gross was initially skeptical and continued to 

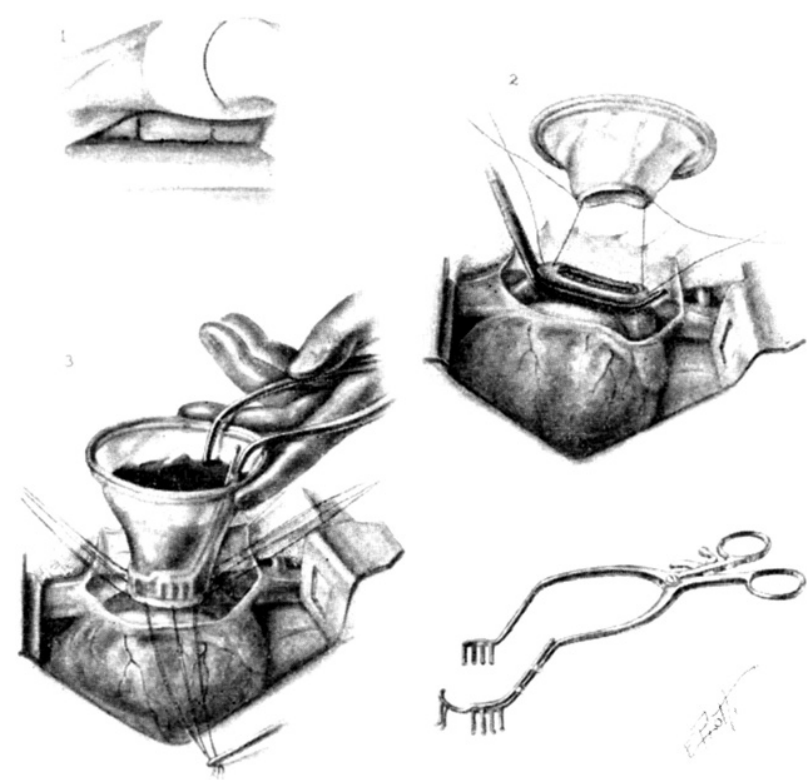

FIGURE 2. Representation of Gross' ingenious atrial well technique for surgical closure of atrial septal defects (courtesy of the New England Journal of Medicine).

favor his atrial well technique. He was relatively slow to adopt the new technology. However, ever the innovator, Gross was working away all the while in the research laboratory to develop his own rotating disc oxygenator. The usefulness of the oxygenator was lessened by the need for a large priming volume of blood. Nonetheless, this cardiopulmonary bypass circuit was used at Children's Hospital until his retirement when he was succeeded by Aldo Castaneda, 74th president of the AATS (Figure 3). The start of the era of open cardiac surgery at Children's Hospital was likely delayed by Gross' slow adoption of the new technology and insistence on the development of his own bypass circuit.

Despite maintaining an active research laboratory throughout his career, Gross never applied for governmental grants. In fact, he did not believe in using government funds to support his research. Instead, he personally raised money for his scientific endeavors from patients and the community. Each year he would host a night at the theater and use the proceeds to support his work. As evidence of the effectiveness of his fund-raising pursuits, Gross purchased and initiated the use of a large hyperbaric chamber that served as an operating room for treating children with congenital heart disease. The theory behind these studies, conducted by Gross and staff surgeon William Bernhard, was that the super-oxygenated environment enabled the surgeon to be more deliberate in performing shunting operations on cyanotic infants. ${ }^{14}$ At the time, the technology was even thought to offer a potential alternative to cardiopulmonary bypass. However, the chamber is probably more notable for its use, albeit unsuccessful, in the

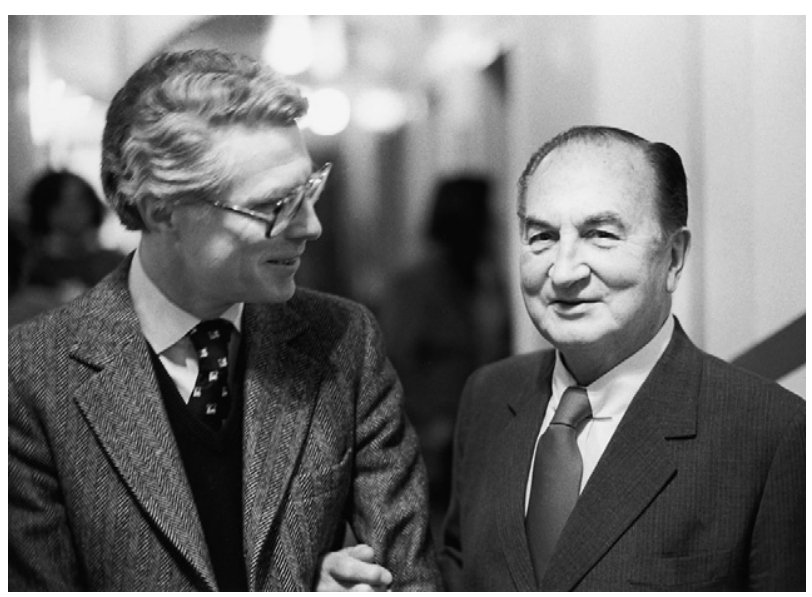

FIGURE 3. Robert Gross meeting with his eventual successor at Children's Hospital, Boston, Aldo Castaneda, during his second visit in the selection process (courtesy of the Children's Hospital Boston Archives).

emergency treatment of President Kennedy's newborn son, Patrick Bouvier Kennedy, who was born prematurely. In the face of repeated media requests during the child's treatment of respiratory insufficiency of prematurity, Gross steadfastly declined comment about his chamber. His well-known shyness and decidedly apolitical nature, coupled with unusual modesty, all likely contributed to his stance.

His research efforts were profound and had direct applicability to patient care. As a result, he received some of the most prominent research honors bestowed on a surgeonscientist. In particular, he was the only 2-time winner of the prestigious American Heart Association Lasker Award, which is given annually "for distinguished achievement in the field of cardiovascular research." He shared the 1954 award with Alfred Blalock and Helen Taussig. His citation read "for distinguished contributions to cardiovascular surgery and knowledge, whereby thousands previously doomed have been restored in health, and hope revived for thousands more... with this achievement, surgery upon the heart and great vessels was at last removed from the realm of experimental trial and placed upon a firm clinical basis." In 1959, he received his second Lasker Award for his "foremost role in the extension of surgery to the relief or cure of other cardiovascular defects."

His influence and leadership spans surgical disciplines, and his accolades are numerous. In addition to serving as president of the AATS, he was also the founder and first president of the American Pediatric Surgical Association. Furthermore, he helped found the American Board of Thoracic Surgery in 1948 and was an early member of the American Board of Surgery. In 1975, he was inducted into the National Academy of Sciences. In 1985, he was honored with the Robert E. Gross Professorship of Pediatric Surgery at Harvard Medical School. 
In the process of founding this new field, he also inspired a generation of future pediatric cardiac surgeons, including John W. Kirklin, 59th AATS president. Kirklin was a Harvard medical student when he first saw Gross in a lecture hall. Kirklin later described the sense of awe that surrounded Gross from all that he had accomplished at such an early age in recounting his first interaction. "He walked in through the right side and had to walk all the way across the room because the lectern was on the left side, and in that walk everybody became a cardiac surgeon."2 To those whom he trained, he was both a surgical mentor and a fatherly figure, appropriately referring to most as "son." He was known to financially support residents through tough times and open his home for extended periods when the need arose. At the same time, he was known to be a taskmaster and could be quite difficult to work for. In one of his more public conflicts, he terminated the operating privileges of his once beloved chief resident in pediatric surgery, Hardy Hendren, shortly after his hiring. Hendren had been a prized pupil of Gross during his training and his perplexing dismissal was both sudden and appeared to lack any substantial basis. Decades later, the two reconciled and fittingly, Hendren became the first Robert E. Gross Professor of Pediatric Surgery at Children's Hospital.

Robert Gross passed away in 1988, 50 years after ushering in the era of closed heart surgery. Countless lives have benefited from his courage to challenge the notion that the human heart and great vessels were irreparable. The field of cardiac surgery will be forever indebted to the work of this true surgical pioneer.

\section{References}

1. Gross RE. Thoracic surgery for infants. J Thorac Cardiovasc Surg. 1964;48: 152-76.

2. Miller GW. The Work of Human Hands: Hardy Hendren and Surgical Wonder at Children's Hospital. 1st ed. New York: Random House; 1993.

3. Cohn LH. Elliot Carr Cutler mitral valve surgery at Peter Bent Brigham Hospital 1923. J Cardiac Surg. 1994;9(2 Suppl):137-8.

4. Gross RE. Surgical management of the patent ductus arteriosus: with summary of four surgically treated cases. Ann Surg. 1939;110:321-56.

5. Lorraine Sweeney interview. Courtesy of the Children's Hospital Boston Archives.

6. Crafoord C, Nylin G. Congenital coarctation of the aorta and its surgical treatment. J Thorac Surg. 1945;14:347-61.

7. Gross RE. Surgical correction for coarctation of the aorta. Surgery. 1945;18: 673-8.

8. Dobell AR. The ductus and the coarctation. Ann Thorac Surg. 1994;57:246-8.

9. Gross RE, Hurwitt ES, Bill AH Jr. Preliminary observations on the use of human arterial grafts in the treatment of certain cardiovascular defects. N Engl J Med. 1948;239:578.

10. Gross RE, Bill AH Jr, Peirce EC Jr. Methods for preservation and transplantation of arterial grafts; observations on arterial grafts in dogs; report of transplantation of preserved arterial grafts in nine human cases. Surg Gynecol Obstet. 1949;88: 689-701.

11. Gross RE. Surgical relief for tracheal obstruction from a vascular ring. $N$ Engl J Med. 1945;233:586-90.

12. Gross RE, Ware PF. The surgical significance of aortic arch anomalies. Surg Gynecol Obstet. 1946;83:435-48.

13. Gross RE, Pomeranz AA, Watkins E Jr, Goldsmith EI. Surgical closure of defects of the interauricular septum by use of an atrial well. $N$ Engl J Med. 1952;247: 455-60.

14. Bernhard WF, Tank ES, Frittelli G, Gross RE. The feasibility of hypothermic perfusion under hyperbaric conditions in the surgical management of infants with cyanotic congenital heart disease. J Thorac Cardiovasc Surg. 1963;46:651-64. 